\title{
Aristotle, Protagoras, and Contradiction: Metaphysics $\Gamma$ 4-6
}

\author{
Evan Keeling \\ USP, Brazil
}

\begin{abstract}
:
In both Metaphysics $\Gamma 4$ and 5 Aristotle argues that Protagoras is committed to the view that all contradictions are true. Yet Aristotle's arguments are not transparent, and later, in $\Gamma 6$, he provides Protagoras with a way to escape contradictions. In this paper I try to understand Aristotle's arguments. After examining a number of possible solutions, I conclude that the best way of explaining them is to (a) recognize that Aristotle is discussing a number of Protagorean opponents, and (b) import another of Protagoras' views, namely the claim that there are always two logoi opposed to one another.
\end{abstract}

\section{Introduction}

Protagoras' famous dictum is:

(M) "Man is the measure of all things: of the things which are, that they are, and of the things which are not, that they are not." (Theaetetus, 152A) ${ }^{1}$

This seems to be the opening line of his book Truth. ${ }^{2}$ Aristotle, however, never quotes the dictum in full, relying for the most part on shorthand formulations like "all beliefs and appearances are true."3 Aristotle clearly takes (M) to be mistaken, and in trying to refute it, he connects it to other, more extreme and thus less plausible claims. But his point is not just to link (M) to these extreme claims and call it refuted. His general aim in this part of Metaphysics $\Gamma$ is to provide a refutation of those who claim to disagree with the principle of non-contradiction (PNC) and thus to provide support for it. ${ }^{4}$ This requires a dialectical refutation of those, like some

\footnotetext{
${ }^{1}$ See also Plato, Cratylus, 385E2-386A2; Aristotle, Metaphysics K 6, 1062b13-15; Sextus Empiricus, M, vii 60-1; Diogenes, Lives, ix 51.

${ }^{2}$ Though Sextus, ibid., says the quotation comes from Kataballontōn, perhaps another name for the same work.

${ }^{3}$ The initial connection between Protagoras' claim and the idea that perceptions are all true is made at Tht. 152A-C. Cf. also Tht. 161C2-3, 161D6-7, 167A7-8, 167D3. For Aristotle, see Met. Г 4, 1007b21-3; Г 5, 1009a7-8; 1009a38-b2; 1010b1-2; Г 6, 1011a19-21; K 6, 1062b13-15.

${ }^{4} \mathrm{He}$ calls his argument an 'elenctic proof' (elenktikōs apodeixai: 1006a11-15). See Code (2010) for a good discussion of Aristotle's method here.
} 
Protagoreans, who claim in words to reject PNC. Aristotle's negative arguments against the Protagoreans are found mainly in three short passages: 1007b18-25 and 1009a5-15 present negative arguments, while a more positive one is found at 1010b1-11a2. This paper focuses solely on the negative arguments. ${ }^{5}$

Whereas Plato discusses Protagoras in the context of a discussion of what knowledge is and develops a Secret Doctrine in part to defend Protagoras from the objection that he is committed to contradictions, Aristotle, in contrast, argues twice that the Protagoreans are committed not just to the contradictory of PNC but to its contrary:

(C) All contradictions are true. ${ }^{6}$

The connection between (M) and (C) is the main idea I wish to explore in this paper. It is a puzzling one, for several reasons. First, it is hard to see how Protagoras could be committed to (C) given another view associated with him. In Plato's Euthydemus, Socrates rehearses an argument to the conclusion that it is impossible to contradict (ouk estin antilegein), a view he tells us Protagoras and his followers used to make great use of (286C). If Protagoras held that it is impossible to contradict, how could he be committed to the view that contradictions are always true? Second, Aristotle's argument that Protagoras is committed to the contrary of PNC is strange because his objective in this part of Metaphysics $\Gamma$ is to defend PNC. And even if he succeeds in refuting the contrary of PNC, this would offer little support for PNC as a general principle. Before discussing Aristotle's arguments in detail, it will be useful to provide a brief response to these questions. Aristotle's arguments here have often been accused of being not only puzzling but weak. Christopher Kirwan (1993: 90) goes so far as to suggest that the arguments in chapter 4 are purposely weak and might have been collected for pedagogical purposes so that Aristotle's pupils could compare and evaluate them. But much of the power of this impression can be dispelled by remembering that Aristotle's aim in addressing opponents like Protagoras is to defend PNC from dialectical objections, i.e., from people who claim to reject the principle in words. Aristotle's arguments, if successful, therefore do provide strong reasons to accept PNC, in that they remove the dialectical objections people give for rejecting it.

\footnotetext{
${ }^{5}$ For a discussion of the positive argument, see my "Aristotle and Protagoras on the Infallibility of Proper-Object Perception: Metaphysics Г 5, 1010b1-1011a2" (unpublished).

${ }^{6}$ This is merely one way of putting a claim Aristotle expresses in different ways: "Everything must be at the same time true and false" (1009a7); "all contradictories are true of the same subject at the same time" (1007b18-19), and "all things are alike false and true" (1011a28-9).
} 
Such people, Aristotle says, require refutation. ${ }^{7}$ His arguments do not and cannot provide a demonstration of PNC, but from an Aristotelian perspective this is not a weakness. In response to the first puzzle, I shall argue that Protagoras is only committed to (C) on certain interpretations of (M). We shall see below that a different interpretation yields a result free from contradiction. Aristotle needn't concern himself to reject (M) on this interpretation-not in a dialogue with those who refuse PNC-for on this reading, (M) does not run afoul of PNC. I turn now to Aristotle's discussions of the Protagorean view. I hope to be able provide some insight into Aristotle's general concerns in this part of Metaphysics $\Gamma$ as well as help us understand Protagoras' position and how it was understood in antiquity.

\section{2. $\Gamma 5$}

I begin with the latter passage, from the beginning of chapter 5:

From the same view proceeds the logos of Protagoras, and both alike must be either true or false. For on the one hand, if all opinions and appearances are true everything must be at the same time true and false. For many men hold beliefs in which they conflict with one another, and all think those mistaken who have not the same opinions as themselves; so that the same thing must both be and not be. And on the other hand, if this is so, all opinions must be true; for those who are mistaken and those who are right are opposed to one another in their opinions. If then, reality is such as the view in question supposes, all will be right in their beliefs. (1009a5-15, Ross's translation slightly modified $)^{8}$

There are two arguments in this passage, one embedded in the other. (This is true also in the passage we will examine from $\Gamma 4$, where Aristotle's general conclusion is that the Protagoreans are committed to the claim that all things are one.) Here the idea is that two claims

\footnotetext{
${ }^{7}$ I thus contrast dialectical opponents from the physicists, whose reason for claiming to reject PNC is their observation of nature. See, e.g., 1009a15 ff. I say they claim to reject it because, according to Aristotle, no one can actually disbelieve the principle (1005b24 ff.).

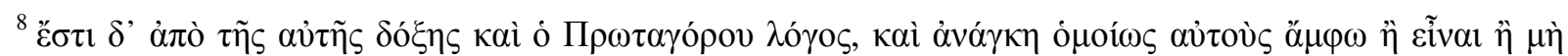

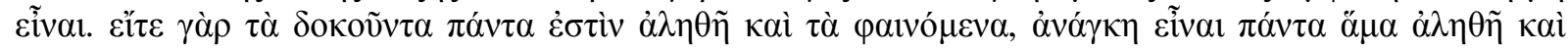

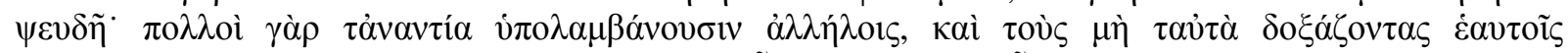

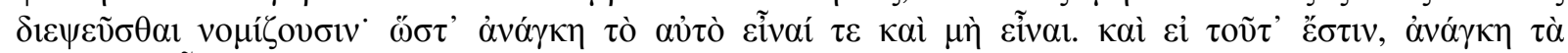

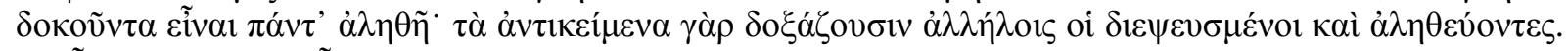

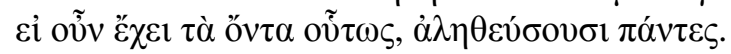


are logically equivalent and that both "proceed from the same way of thinking" (1009a15-16). ${ }^{9}$ It is the inner argument that concerns us here. Aristotle tries to establish a strong logical connection between two claims: first, Protagoras' logos, given as "all opinions (dokounta) and appearances (phainomena) are true" — henceforth (P) —and, second, the contrary of PNC, "everything (panta) must be at the same time true and false," a version of $(\mathrm{C}) .{ }^{10}$ The logical connection Aristotle argues for is inter-entailment: (P) implies (C), and (C) implies (P). So the conclusion of Aristotle's argument is: all opinions and appearances are true if and only if everything is simultaneously both true and false.

Aristotle is careful to argue for both sides of the entailment, even though the second is trivial. But he is not careful in all aspects of the argument. For instance, in arguing that (P) entails (C), instead of repeating the conclusion that everything is at once true and false he offers instead: "the same thing ( moved from a semantic version of the claim to an ontological one; and (b) 'to auto' ('the same thing') replaces 'panta' ('everything'). And in the argument that (C) implies (P), Aristotle has dropped the part of (P) referring to appearances. Now, most of these changes are clearly innocuous. The change from a semantic to an ontological version of (C), though it might have philosophical implications, probably was not considered important by Aristotle. This change continues to the end of the passage, where (C) now is characterized in terms of being (ta onta). This should not trouble us much, because here as elsewhere in Met. $\Gamma$ Aristotle is not always careful to distinguish what is true from what is real or has being; or, rather, he speaks in both ways apparently indifferently. PNC itself is presented both in terms of statements (1011b13-15) and in terms of attributes of things (1005b19-24). ${ }^{11}$ And in Plato's self-refutation argument (Tht. 170-1), he too slides between what is and what is true. However, the other discrepancy is not

\footnotetext{
${ }^{9}$ There is some dispute both over the nature of the two views and what 'same way of thinking' they proceed from. Lee (2005: 120-1) argues that "the same view" is not that everything is both true and false but that being is identical to the sensible world (1010a1-3). See also Wedin (2004: 121-2).

${ }^{10}(\mathrm{P})$ allows qualifiers like for one, while here Aristotle does not mention them. I discuss this apparent discrepancy in $\S 3$ below.

${ }^{11}$ However, the semantic version has some claim to precedence. For at the end of his defense of PNC, Aristotle says it has been shown that the most certain of all beliefs is that "opposite statements

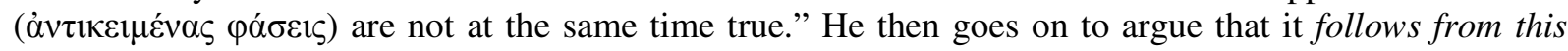
that "contraries also cannot belong at the same time to the same thing" ( $\Gamma$ 6, 1011b13-22). Aristotle, therefore, thinks that the ontological claim ought to be derived from the semantic one, and (presumably) not the other way around.
} 
easily explained away. Why does Aristotle change "everything must be at the same time true and false" to "the same thing must both be and not be"? This anomaly is not found only here. As we shall see, the same expression is used in $\Gamma 4$ in a version of $(\mathrm{C})$ : "the same thing will be a trireme and a wall and a man" (1007b21-2). What is the significance, if any, of this change? I return to these questions later in the paper.

$$
2.1(C) \rightarrow(P)
$$

Let us now turn the argument in detail. I begin with the second half of the argument: that (C) entails (P). It is brief and puzzling: "And on the other hand, if this [the same thing both is and is not] is so, all opinions must be true; for those who are mistaken and those who are right are opposed (ta antikeimena) to one another in their opinions." One reason the argument is puzzling is that the claim that $(\mathrm{C})$ entails $(\mathrm{P})$ is trivial. Aristotle could have said simply that if everything is both true and false, as (C) says, everything is true. And if everything is true, all beliefs are true. ${ }^{12}$ But rather than arguing in this straightforward way, Aristotle somehow makes use of the fact that people hold opposing opinions. It is hard to see how it is relevant that opinions are often opposed to one another; all we need to get to $(\mathrm{P})$ is to notice that $(\mathrm{C})$ ensures that all beliefs are true.

None of the commentators provides much guidance on this issue, nor in general on the argument that $(\mathrm{C})$ implies $(\mathrm{P}) .{ }^{13}$ Does Aristotle mention conflicting beliefs simply for reasons of symmetry: the other half of the argument involves conflicting beliefs, so this one should too ${ }^{14}$ If this seems unlikely, we might start to consider the possibility that we have somehow

\footnotetext{
${ }^{12}$ Or, if one prefers an ontological version of $(\mathrm{C})$ : since everything both is and is not $\mathrm{F}$, all beliefswhether one says that a thing is $\mathrm{F}$ or that it is not $\mathrm{F}$-will be true.

${ }^{13}$ Alexander of Aphrodisias (302,20-34) reconstructs the argument as follows. When a certain affirmation is true, the negation of that affirmation is an error, and vice versa. This is so because when people have opposing opinions, it is possible for one of them to be in error. But this is impossible if all contradictions are true. On this reconstruction it is unclear what role error and opposition play. Ross (1924), Kirwan (1993: 106), and Lee (2005: 65) all gloss over the argument with little or no comment.

${ }^{14}$ Conflicting opinions also come up in the Theaetetus' self-refutation argument of 170-1, but there the crucial role is played by higher-order interpersonal beliefs such as Protagoras believes that Socrates believes that $(M)$ is false. Here the argument must be more general if it is to reach its conclusion that everything is true and false.
} 
misunderstood Aristotle's argument. A partial solution might be found by reinterpreting (C) along the lines suggested by the way Aristotle's later versions of the claim, as:

(S) The same thing is both $\mathrm{F}$ and not-F.

Unless 'the same thing' is generalized to include everything, the argument is no longer trivial. If, for instance, Socrates both is and is not a man, then every belief about whether Socrates is a man will be true. But this change does not help with the issue of conflicting opinions, as the move from (S) to $(\mathrm{P})$ still does not require conflicting opinions. For this reason I do not recommend this change. Still, we do require an explanation for why Aristotle at times speaks of the same thing and at other times everything. This and other puzzling aspects of the argument will have to await an explanation until later. My suggestion, which I shall describe in more detail below, is that in his mention of conflicting beliefs Aristotle is here smuggling in another Protagorean thesis.

$$
2.2(P) \rightarrow(C)
$$

The other half of Aristotle's argument is, if anything, even more puzzling:

"For on the one hand, if all opinions and appearances are true everything must be at the same time true and false. For many men hold beliefs in which they conflict with one another, and all think those mistaken who have not the same opinions as themselves; so that the same thing must both be and not be."

At first glance, the argument seems to be the following:

(1) All beliefs and appearances are true

(2) People often have beliefs which conflict with the beliefs of others

(3) Everyone thinks anyone with a different opinion is mistaken

Therefore:

(4) Everything is both true and false ${ }^{15}$.

The argument as it stands is puzzling. The role played by premise (3) is obscure, and the move to the conclusion requires explanation. As M.K. Lee points out, the argument as presented contains two gaps. First, it seems to assume that for the Protagorean, all truths are believed. That

\footnotetext{
${ }^{15}$ Lee (p. 65) adds the premise that those with conflicting beliefs also believe the others are mistaken. This hits on a point important for Plato's version of the argument but seems not to be needed here.
} 
is, Aristotle here interprets (M) as claiming not only that all beliefs are true but also that all truths are believed. If there were unbelieved truths, there would be no way to connect the premise that people have conflicting beliefs with the conclusion that everything is both true and false. The other gap is that he assumes that for every belief, there is someone who holds its negation, i.e. that for every belief someone can be found who holds its negation. Lee therefore adds the following two premises to obtain a valid argument:

(5) For every belief, there must be someone who disagrees with it and

(6) Nothing is true unless someone believes it to be true.

Justifying (6) is fairly easy. Protagoras clearly holds that belief is sufficient for truth, but does he also hold that it's necessary? Michael Wedin ("Animadversions," 181-4) argues against this biconditional reading of the measure doctrine because it would require us to say about a case in which the subject has no doxastic attitude at all towards some proposition, that the proposition is nevertheless false for him. This, he claims, goes against the spirit of Protagoras' measure doctrine, which he says, "just is a doctrine about agents' doxastic attitudes" (p. 183). And again: "the very idea of someone's being a measure requires that he display some doxastic attitude towards whatever he is the measure of" (p. 182).

But despite some resistance among scholars, Protagoras clearly is commited to the biconditional reading of $(\mathrm{M})$, and we don't need Aristotle to tell us this. ${ }^{16}$ But obligingly, Aristotle is clear both that Protagoras must hold the biconditional that belief is both sufficient and necessary for truth, and also why he must do so. He believes Protagoras is committed to the biconditional because he thinks, correctly, that $(\mathrm{M})$ requires this. Advocates of $(\mathrm{M})$ who argue for the sake of argument "must make everything relative-relative to belief [doxan] and perception so that nothing either has come to be or will come to be without someone's first thinking so [prodoxasantos]" (1011b4-7). ${ }^{17}$ The issue Aristotle has put his finger on is one that some advocates of what is called the biconditional reading of $(\mathrm{M})$ in the Theaetetus have noticed. As Mehmet Erginel puts it, rejecting the biconditional reading would be "inconsistent with the notion that man is the measure of all things, for there could be, on this view, a lot of things that

\footnotetext{
${ }^{16}$ Though few scholars discuss the issue in the context of Aristotle, the majority of scholars subscribe to the biconditional reading, at least in the Theaetetus. This includes Burnyeat, Fine, and Lee.

${ }^{17}$ See also Met. $\Theta 3,1047 \mathrm{a} 4-6$.
} 
are true in A's world independently of A's belief system, i.e. a lot of things of which A is not the measure" (22). The doctrine is a claim about the relation between doxastic attitudes and what is. If we reject the biconditional reading of $(\mathrm{M})$, we are left with the possibility that there are truths in my world which I don't believe and thus which I am not the measure of. In general, there can be no proposition, $p$, which is true in my world but which I don't believe. As Erginel says, this would be inconsistent with the notion that I am the measure of all things. ${ }^{18}$ Aristotle is correct that Protagoras is committed to the biconditional reading, and (6) is justified.

\section{Some Problems}

Before turning to the other main passage and the questions it raises, there is more to be said about the latter chapters of book $\Gamma$. We have seen that one of Aristotle's main conclusions appears to be that (M) and thus (P) implies the view that everything is both true and false. But in a later passage, from $\Gamma 6$, Aristotle seems to have quite a different view of the matter:

If not all things are relative [pros ti], but some are (whatever they are) in themselves, not everything that appears will be true; for that which appears [to phainomenon] appears to someone; so that he who says all things that appear are true, makes all things relative. And, therefore, those who ask for an irresistible argument, and at the same time are willing to take a stand in argument, must guard themselves by saying that the truth is not that what appears is the case, but that what appears is the case for him to whom it appears, and when, and to the sense to which, and under the conditions under which it appears. And if they give an account of their view, but do not give it in this way, they will soon find themselves contradicting themselves. ( $\Gamma$ 6, 1011a17-25, Ross's translation slightly modified)

In contrast to the argument discussed above, here Aristotle outlines a way for an advocate of pros $t i$ (relativity) to avoid contradictions: he must add the appropriate qualifiers to all his claims about what appears. His reference to the truth of appearances doctrine indicates that some

\footnotetext{
${ }^{18}$ Wedin addresses this worry (at pp. 183-4 n14), saying that the biconditional reading (a) might "provide additional support" for the measure doctrine but would have to be gotten by means of an "extra step". And (b) that, even so, since Protagorean worlds are private worlds, no one can be a measure of all truths, as there are truths in other people's worlds, in which the occupier(s) of those other worlds are the measures of them, not me. Both points are wrong. First, as I have argued, the biconditional reading is simply a consequence of the measure doctrine, not an additional support. If I am the measure of all things, there can be nothing - at least nothing in my world —of which I am not the measure. There cannot exist unbelieved truths or unknown properties or objects. Second, it is true that Protagorean worlds are private in the Theaetetus, at a certain stage of the dialectic. But private worlds are undermined and rejected in the passage just before the self-refutation argument and, as Wedin himself points out elsewhere (2003, 127 n25), appear nowhere in Aristotle's discussion.
} 
group of Protagoreans is at issue. Aristotle then goes on to provide his own analysis of the situation:

For to those who for the reasons named above say that what appears is true, and therefore that all things are alike false and true, for things do not appear either the same to all men or always the same to the same man, but often have contrary appearances at the same time (for touch says there are two objects when we cross our fingers, while sight says there is one), - to these we shall say, 'yes, but not to the same sense and in the same part of it and in the same way and at the same time,' so that what appears is under these qualifications true. ${ }^{19}$ (1011a28-b1, Ross)

In the $\Gamma 5$ passage discussed above, 1009a5-15, Aristotle argues that Protagoras' logos implies that everything is both true and false. Yet here, Aristotle provides them a strategy to avoid contradicting themselves. In the second passage quoted, the advocate of the truth of appearances endorses (or at least is committed to) the move from all appearances are true to "all things are alike false and true" (panth' homoiōs einai pseudē kai alēthē). And as we have seen, this is the very conclusion Aristotle accused the Protagoreans of being committed to earlier, in very similar language (cf. einai panta hama alēthē kai pseudē, 1009a9). In the first passage, by contrast, Aristotle shows them a way to avoid the conclusion. By adding the appropriate qualifiers to all their appearance claims, Aristotle shows them how to avoid the unfortunate consequence and also why, when understood properly, appearances do not really conflict. This discrepancy is difficult to explain.

Why, then, does Aristotle connect Protagoras with contradictions at all? One answer is that Aristotle is attacking an extreme version of the Protagorean claim, one that involves rejection of the PNC. ${ }^{20}$ But I prefer the following explanation. In the arguments from $\Gamma 4$ and 5, Aristotle does not allow the Protagoreans to add qualifiers to their claims. On this reading, advocates of the view will naturally find themselves rejecting PNC and so require a refutation.

\footnotetext{
${ }^{19}$ After 1011a28-b1 Aristotle suggests that those who argue for the sake of argument can say not that this is true, but true "for this man" (1011b1-3). He then concludes his discussion of PNC with the following suggestion, and finally with a convoluted argument against a form of relativism: "As has been said before, they must make everything relative-relative to opinion and perception, so that nothing either has come to be or will be without someone's first thinking so. But if things have come to be or will be, evidently not all things will be relative to opinion" (1011b4-7).

${ }^{20}$ P. Gottlieb, 1994, "The Principle of Non-Contradiction and Protagoras: The Strategy of Aristotle's Metaphysics IV 4", Proceedings of the Boston Area Colloquium in Ancient Philosophy, p. 192, suggests that it is because Aristotle is attacking the position of Theaetetus 183, which includes the rejection of PNC. Gottlieb has also suggested (in conversation) that to the extent that the Protagoreans reject substance and essence, they are also forced to deny PNC in general and cannot add qualifiers. See $\$ 4.2$ below for discussion of a similar suggestion.
} 
We can speculate that there might have existed Protagoreans of this sort, who claimed to deny PNC because of their belief in the truth of appearances. But Aristotle recognizes other ways of understanding the view. What I am suggesting is that the Protagorean view that "what appears is true" is open to a number of different interpretations and origins and that $\Gamma$ 4-6 presents a number of these. Some of those who accept this view do so for the sake of the argument. Some members of this group do not add qualifiers and are thus subject to dialectical refutation such as we saw in $\Gamma 5$ and will see below in $\Gamma$ 4. In 1011a17-25, quoted above, we learn about another group - this time, of people willing to add qualifiers. This group requires no refutation here because by adding the appropriate qualifiers, they do not reject PNC. Another complicating factor is that Aristotle recognizes two different general types of opponent: those who hold their view for the sake of the argument, and those who have been reasoned into it. The former require dialectical refutation, while the latter need to be shown that their grounds for believing their view are problematic. The last passage quoted, 1011a28-b1, discusses some Protagoreans members of this latter group. They have come to believe Protagoras' view "for the reasons named above"presumably, reasons such as the observation that from the same thing come opposite qualities. (An example of this is that the same leaf can be at one time red and at another time brown, or not-red.) Aristotle's strategy against this group involves making them familiar with certain distinctions, which will help explain why their Protagorean conclusion does not follow.

To get a historical sense of why there might have been many different 'Protagoreanisms', let's take a quick look back at the Theaetetus. Socrates' original example (Tht. 152B) is of the same wind's feeling cold to one person and not cold to another. Here, both the statement (or belief or appearance) that the wind is cold and the statement that it is not cold must count as true. ${ }^{21}$ Generalize this point and we begin to see why Aristotle thinks there are at least some Protagoreans committed to the view that everything is both true and false. The statement that the wind is cold is true because believed by one person but false because someone else believes that the same wind is not cold. This seems to me to go some way towards explaining the puzzling discrepancy I mentioned earlier: that at times, Aristotle argues that Protagoras' logos implies not that "everything is true and false" but that "the same thing will both be and not be." No doubt this was thought by at least some followers of Protagoras to have been problematic, as it entails the denial of PNC. But the rest of the story is not determined by (M) and can change depending

\footnotetext{
${ }^{21}$ Here I follow a suggestion made by G.B. Kerferd, The Sophistic Movement, p. 92.
} 
upon the particular advocate of Protagoreanism. Any number of possible solutions might have been used, including those we find in the Secret Doctrine of the Theaetetus and many others. Different groups of Protagoreans will require different strategies. ${ }^{22}$

This leaves us still with some difficult questions. First, we have still not fully understood why Aristotle at first connects Protagoras to the view that all contradictions are true, or that everything is both true and false, and then later offers a solution to just this problem. Second, we have not seen how Aristotle connects Protagoras to this radical view in the first place, nor exactly what his purpose is. Why is it that Aristotle seems to think Protagoras is committed to the completely general claim that everything both is and is not? How does he move from the plausible idea that disagreement is always possible to the seemingly absurd idea that it is actual? These issues arise again in what follows.

\section{4. $\Gamma 4$}

In $\Gamma 4$ Aristotle discusses similar themes:

(1) Again, if all contradictories are true of the same subject at the same time, evidently all things will be one. For the same thing will be a trireme, a wall, and a man, if it is possible to affirm or to deny anything of anything, - and this premise must be accepted by those who state the logos of Protagoras. For if any one thinks that a man is not a trireme, evidently he is not a trireme; so that he also is a trireme, if the contradictory is true. $(1007 \mathrm{~b} 18-25, \text { modified })^{23}$

There are some obvious similarities between this and the $\Gamma 5$ passage discussed above. But there are also some new ideas. One interesting difference is that while the argument of $\Gamma 5$ is conducted in terms of belief, this argument is conducted mainly in logico-semantic terms, involving what is affirmed and denied. But Protagoras' logos does play a role, in the familiar claim that belief or appearance (dokei) is sufficient for truth. Another new idea is found in the

\footnotetext{
${ }^{22}$ Lee (pp. 71-2) argues that the latter passages I have mentioned show that Aristotle thinks there are two ways for Protagoras to avoid contradictions. One is to relativize all statements; the other is to add 'is true for' to all statements. The former suggestion is for those who argue due to problems in their thinking; the latter applies to those who argue for argument's sake. She interprets the latter suggestion as semantic relativism about truth. However, I see nothing to suggest that these are two different strategies.

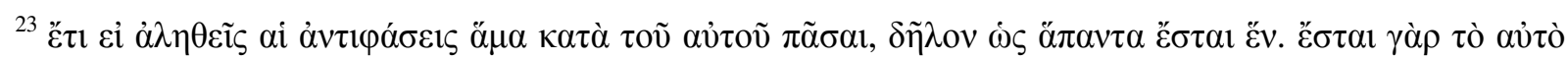

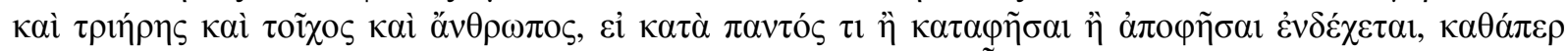

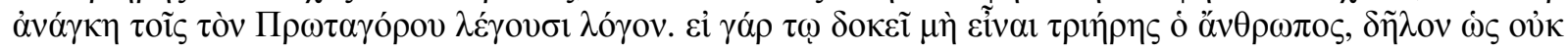

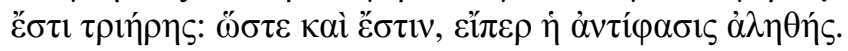


passage's opening, which says that "if all contradictories are true of the same subject at the same time," then "all things will be one." What does it mean to say "all things will be one"? Kirwan says it means everything has and does not have every property. Wedin objects that this would make the claim simply a gloss of the contrary of PNC, making it unclear why Aristotle feels the need to argue that advocates of the contrary of PNC are committed to it (2003, p. 111). He suggests instead that it might mean that everything has all the same positive properties. This would follow from the idea that: if it's possible that any two things hold, it's separately possible that each of them holds (ibid.). And this, Wedin says, might force the Protagoreans into the additional embarrassment that all things have the same attributes-additional to the embarrassment that all contradictory properties hold good.

Pace Kirwan and Wedin, the apparent meaning of "everything will be one" is: there is exactly one object. And there is good reason to think this claim follows from the claim that all contradictories are true of the same object. ${ }^{24}$ It follows from the idea that all contradictories are true of the same subject at the same time. For, assuming all things have all contrary properties, every possible attribute can be truly ascribed to every object. Thus every object would have every property. By Leibniz's Law, if $x$ and $y$ have all the same properties, $x$ is identical to $y$. If all things have all the same properties, then everything will be identical, and there will be exactly one object. But here again we need not rely solely on speculation, as Aristotle makes it clear what he means in a later passage:

And all things will on this view be one, as has been already said, and man and God and trireme and their contradictories will be the same. For if contradictories can be predicated alike of each subject, one thing will in no wise differ from another; for if it differ, this difference will be something true and peculiar to it. And if one may with truth apply the predicates separately, the above-mentioned result follows none the less. $(\Gamma 4,1008 \mathrm{a} 23-28, \text { Ross })^{25}$

This passage confirms my suggestion that "everything will be one" means "there will be exactly one object." If we can truly predicate of Socrates both man and not-man, the distinction

\footnotetext{
${ }^{24}$ I will not speculate as to why it is problematic for the Protagoreans to be connected with this extreme claim. But it's interesting to note that in the Theaetetus the Protagoreans and Heracliteans are contrasted with the Parmenideans, whereas here they are connected.

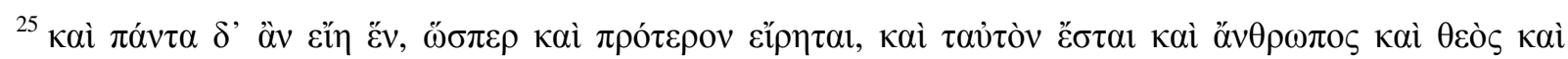

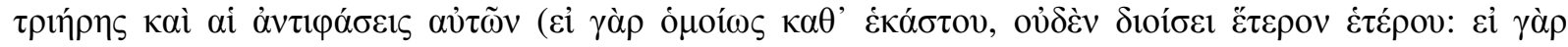

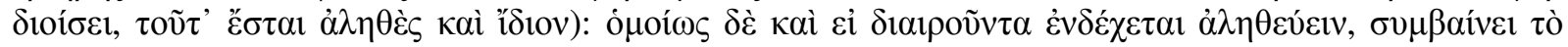
$\lambda \varepsilon \chi \theta \dot{\varepsilon} v$.
} 
between men and other sorts of things dissolves. Do this for all predicates and "one thing will in no wise differ from another."

Aristotle claims that "everything will be one" follows from the idea that "all contradictories are true of the same subject at the same time.” This latter claim is just (S), which as I said in discussing the argument from chapter 5 is, perhaps, a weakened version of (C). So Aristotle is claiming that $(\mathrm{S})$ or $(\mathrm{C})$ entails that there is exactly one object. But the rest of the passage does not flesh out this argument, perhaps because it seems obvious to Aristotle. Instead, he goes on to argue that these extreme views must be accepted by the Protagoreans. To establish this connection, Aristotle connects the logos of Protagoras to the claim that "it is possible (endechetai) either to affirm or to deny everything of everything." ${ }^{26}$ This latter claim then entails that a man is both a trireme and not a trireme. Now, it is correct to say that Protagoras' logos implies that it is possible either to affirm or deny anything of anything. But why must the Protagoreans accept the second conclusion - that a man is both a trireme and not a trireme? Aristotle's answer is that if anyone thinks a man is not a trireme, this will be true; and he will also be a trireme, if the contradictory is true. ${ }^{27}$ Thus the argument somehow proceeds from Protagoras' logos through "it is possible either to affirm or to deny something of everything" to "everything will be one." Schematizing the argument:

(1) All affirmations are true (Protagoras' logos)

This implies:

(2) It is possible to affirm or deny anything of anything

Therefore:

(3) The same thing will be a trireme, a wall and a man

Generalizing (3) we get:

(4) All contradictories are true of the same object at the same time

\footnotetext{
${ }^{26}$ One could object that Aristotle only says that it is possible to affirm or deny something ( $\left.\tau\right)$ of everything. This, in fact, is how Wedin reads and translates the text (though both Ross and Tredennick translate ' $\tau$ ' ' as 'everything'). This provides some ammunition for Wedin's suggestion that the argument continues into the next passage. I agree with this suggestion, but I disagree with Wedin's general reading. See below.

${ }^{27}$ It is not clear to me whether the idea is that man (the predicate) is the same as the predicates trireme, wall, etc., or that a particular man is also a trireme, wall, etc. The latter argument is suggested by a later passage, but it seems to me that the former argument could be made in a similar way. I will formulate the argument in terms of substances and objects, but again I believe a very similar argument could be made in terms of properties.
} 
(5) There exists exactly one object (from (4) and Leibniz's Law).

I have already argued that (5) follows from (4). But why is Protagoras committed to (2), that "it is possible either to affirm or to deny anything of anything"? And why should a Protagorean agree to generalizing (3)?

A consequence of Protagoras' logos is that our beliefs (and so long as they follow them, our predications as well) are always true. If whatever I believe is true, as Protagoras claims, it follows that I needn't be concerned with my beliefs' "hitting the target"; they will always, somehow, be correct. Aristotle's examples in this part of the text include man, wall, trireme, and God. These are plausible candidate substances, but otherwise there is nothing special about them. So from the idea that we can predicate of the same thing trireme, wall, and man, we can generalize this for all predicates. I take it that Aristotle's choice of predicates is arbitrary and that we can move from the same thing can be said to be a man, a wall, and a warship to the same thing can be any $F$. Couple this with the idea I have been describing and the result is something approaching (4), that: the same thing could be F, for all $F$. The class of $F$ things needn't be limited to positive qualities, and we can also include all negative properties, like not-being-atrireme. We can conclude that from Protagoras' logos it follows that the same thing could be $F$ and not-F, for all $F$.

\subsection{The Problem of Universal Disagreement}

But there is still a problem-in fact, the same problem that arose in our discussion of the $\Gamma 5$ argument. The argument seems to require something like universal disagreement (UD). For, in spite of all I've said, (4) does not follow from (3). The most I have been able to establish thus far on Aristotle's behalf is that the same thing could be F and not-F, for all F, not that the same thing is both $\mathrm{F}$ and not-F. And without this crucial step, there seems to be no way for Aristotle's argument to reach its conclusion that all things must be one. All that follows is the modal claim that the same thing could be a man, a wall and a warship - given that someone predicates these properties of it or that someone believes it. To show that Protagoras is committed to the view that all things are one, Aristotle must find a way to link Protagoras either with the idea that for every belief there can be found someone who will disagree, i.e., UD, or with some logico-semantic point which forces him to move from what is predicable to what is predicated, and thus to what 
is true. In the $\Gamma 5$ argument, Aristotle conceals the fact that he needs universal disagreement by writing that, "many men (polloi) hold beliefs in which they conflict with one another." ${ }^{, 2}$ But as we have seen, his argument seems to require the universal claim that disagreement is found always and everywhere. And why should anyone, including Protagoras, endorse this? As Kirwan (1993: 106) asks, "Who believes...that e.g. Socrates is a warship?"

It seems that Aristotle has smuggling UD into the argument. However, there is no hint that Aristotle is making use of UD in the $\Gamma 4$ passage. So perhaps Aristotle thinks there is some other way to link (4) and (5). Can it be shown that possible (not actual) belief is enough for the truth of a proposition, on Protagoras' view? Given 1011b4-7, the answer seems to be no: Aristotle apparently thinks actual belief is necessary for truth, for those who argue for the sake of the argument. This group, I have argued, includes the Protagoreans addressed in the $\Gamma 4$ passage. Since there is no suggestion here in $\Gamma 4$ that anyone actually believes that, for instance that Socrates is a warship, there seems to be no way to link Protagoras with UD. And even if someone could be found who actually believes this absurd claim, surely this is not true for every claim.

Another solution would be to show that Protagoras is committed to the idea that everything is indeterminate. ${ }^{29}$ If everything in some sense has all properties, there would be no question of ever having a false belief. Indeed, Aristotle links the Protagoreans with Anaxagoras in a second passage, immediately following passage (1):

(2) And the result is the dictum of Anaxagoras, "all things are mixed together"; so that nothing truly exists. It seems, then, that they are speaking of the Indeterminate; and while they think that they are speaking of what exists, they are really speaking of what does not; for the Indeterminate is that which exists potentially but not actually. (1007b25-29)

If Protagoras were committed to Anaxagoras' claim of indefiniteness, our problem would be easier to solve. For if "all things are mixed together," actual belief is not required to make a thing both $\mathrm{F}$ and not-F. Things will naturally, primordially be whatever one thinks they are. But in spite of Aristotle's linkage, this is not a promising way to plug the hole in the argument, for two reasons. First, even though indefiniteness would succeed in patching a hole in the argument, it patches it in the wrong way. If Anaxagoras is right, there's nothing special about man's powers

\footnotetext{
${ }^{28}$ Cf. also Met. K $1062 \mathrm{~b} 18$ where he uses the word 'pollakis.'

${ }^{29}$ Indeed, Porphyry (DK 80B2) reports that Protagoras argued against those who make being one. But I take this to be a consequence of the measure doctrine, rather than a separate Protagorean doctrine.
} 
of belief; it just happens to be that everything is mixed together, indeterminate. ${ }^{30}$ Even though it would guarantee the truth of all views, it wouldn't be because of the belief that the belief is true. It would be simply in the nature of things. This would make Protagoras' view into a fundamentally ontological rather than an epistemic one. The second reason is that Anaxagorean indefiniteness is said to be a consequence of Protagoras' position, not a support for it. And in order to show that Protagoras is committed to Anaxagorean indefiniteness, we will have to already assume something like universal disagreement. Anaxagorean indefiniteness is quite general, and only an equally general Protagorean thesis could be said to commit one to it.

If Anaxagorean indefiniteness fails to explain Aristotle's arguments, let's continue:

(3) But they must predicate of every subject every attribute or the negation of it. For it is absurd if of every subject its own negation is to be predicable, while the negation of something else which cannot be predicated of it is not predicable of it; for instance, if it is true to say of a man that he is not a man, evidently it is also true to say that he is either a trireme or not a trireme. If, then, the affirmative can be predicated, the negative must be predicated too; and if the affirmative is not predicable, the negative, at least, will be more predicable than the negative of the subject itself. If, then, even the latter negative is predicable, the affirmative will be so too. (1007b29-1008a2, Ross modified $)^{31,32}$

This passage seems to offer more hope in filling the gap I outlined above. Despite its opening line, the passage intends to show that the Protagoreans must predicate of every subject every attribute and the negation of it. Before trying to reconstruct the argument, we need to take a closer look at the first line, which is one expression of the argument's conclusion. I have modified Ross's translation to better reflect the Greek, though in fact, as I will argue, Ross's

\footnotetext{
${ }^{30}$ But cf. $\Gamma$ 7, 1012a25 ff. Here Aristotle says that Anaxagoras' idea that all things are mixed "seems to imply an intermediate in contradiction, so that all things are false; for when things are mixed, the mixture is neither good nor not-good; and so no statement is true."

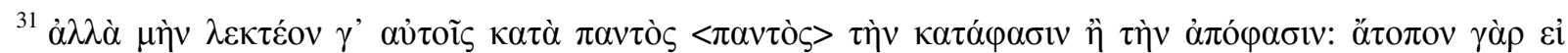

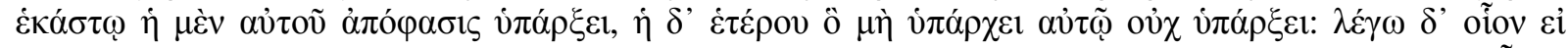

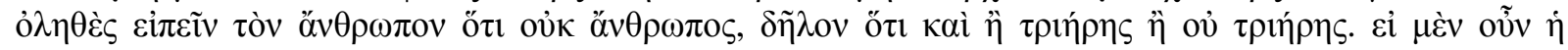

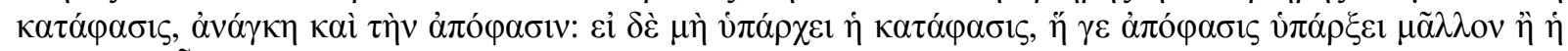

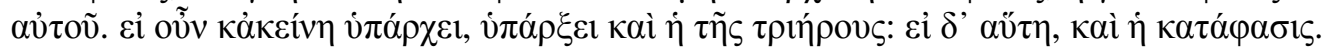

${ }^{32}$ Wedin (2003, 117), following Kirwan, translates the passage as follows: But certainly [vi] their statements, at any rate, must affirm or deny everything of everything, for [vii] it would be absurd if the denial of itself held good of each thing, but the denial of some other thing, which does not hold good of it, did not hold good of it. I mean [viii] for instance that if it is true to say of a man that he is not a man, plainly [ix] he is also either a warship or not a warship, so [x] if the affirmation holds good of him, so also must its denial; but [xi] if the affirmation does not hold good, at least its denial will hold good of him more readily than his own. So [xii] if even the latter does hold good, that of warship will too; and if it does, its affirmation will too.
} 
interpretation is correct. Ross actually translates, "they must predicate of every subject every attribute and the negation of it indifferently." Wedin, following Kirwan, reads: "their statements, at any rate, must affirm or deny everything of everything." 33 This seems to be another case of Aristotle's carelessness, since here again we have a discrepancy about the conclusion of the argument. For Ross's reading, if not his translation, is confirmed by the way the passage ends. Wedin translates: "So if even the latter [negation] does hold good, that of warship will too; and if it does, its affirmation will too." The point here is clearly that both the negation and affirmation of warship will hold, which when generalized yields the conclusion that all predicates can be affirmed and denied. So while Ross is guilty of over-translating the argument's opening line, his reading is nevertheless correct. (As even Wedin admits, the other reading is rather trivial.) Ross's reading of the passage's conclusion also gains support in light of the following passage:

(4) Further, it follows that all would then be right and all would be in error, and our opponent himself confesses himself to be in error. -And at the same time our discussion with him is evidently about nothing at all; for he says nothing. For he says neither 'yes' nor 'no', ${ }^{34}$ but both 'yes' and 'no'; and again he denies both of these and says 'neither yes nor no'; for otherwise there would already be something definite. - Again, if when the assertion is true, the negation is false, and when this is true, the affirmation is false, it will not be possible to assert and deny the same thing truly at the same time. But perhaps they might say we had assumed the very thing at issue. $(1008 \mathrm{a} 29-35)^{35,36}$

The conclusion follows from the notion that even a thing's 'own negation' (autou apophasis) is predicable of it. Given that not-A is predicable of A, e.g. given that a man is also a non-man, a fortiori everything else is also predicable of A. Take, for instance, a generallyrecognized man like Socrates. The assumption Aristotle is operating with is that even non-man is predicable of this obvious example of a man. The point is that if even a generally-recognized man, such as Socrates, is also not a man, then surely we can just as reasonably say he is

\footnotetext{
${ }^{33}$ Cf. also Tredennick.

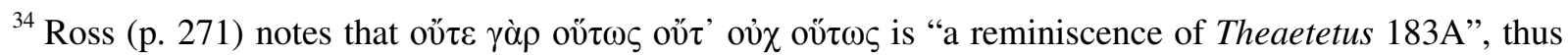
implicating the Protagoreans.

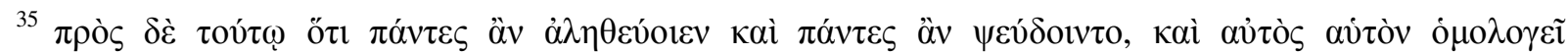

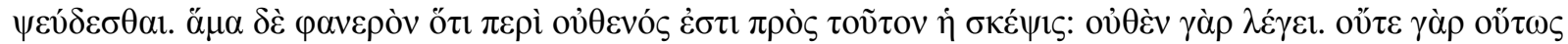

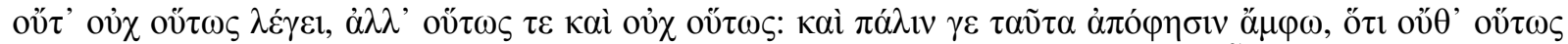

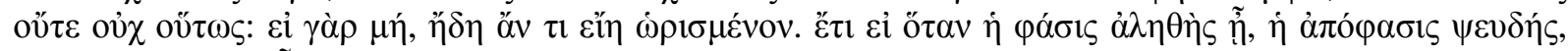

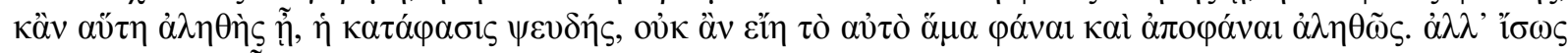

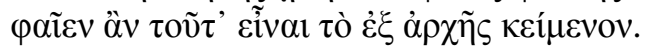

${ }^{36}$ See also $\Gamma$ 8, 1012b15-22.
} 
anything - that he is both a trireme and not a trireme, for instance. Ross summarizes the argument in passage (3) as follows:

But they [the Protagoreans] must admit that any predicate may be affirmed and denied of any subject. For if not-A is predicable of A, not-B will a fortiori be predicable of A. If, then, A is B, it is also not- $\mathrm{B}$; and if it is not $\mathrm{B}$, it must be not- $\mathrm{B}$ more than it is not-A. Since, then, A is not-A, it is a fortiori not-B, and therefore B. (Ross, 1924, pp. 266-7, italics in original).

Ross's reconstruction is accurate but compressed. He is correct in particular that the argument is an a fortiori one. To make things more conspicuous, I will try to reconstruct Aristotle's argument in more detail. The conclusion is something like:

If a thing's own negation is predicable of it, all negations (and indeed all properties) must be predicable of it

I take a thing's own negation to be the negation of a property it has obviously and by nature. The assumption that a thing's own negation is predicable of it and what this implies will be discussed below. Aristotle illustrates the point by means of an example:

If a man is also a non-man, he is also either a trireme or a non-trireme

This sets up a dilemma: being a trireme either is or is not predicable of the man. On the first horn we get:

If trireme is predicable of the man, we must also predicate non-trireme of him

The reason is that, since we have assumed that even a thing generally recognized as a man is also not a man, since he is also a trireme, a fortiori he will also be not a trireme. On the second horn:

But if trireme is not predicable of the man, at least non-trireme will be more predicable of him than non-man.

Therefore, if even non-trireme is predicable of the man, trireme will also be predicable of him

This bit of the argument is quite difficult. What sense can be made of the idea that something is more predicable than something else? My best guess is that it is another instance of a fortiori reasoning. If the Protagorean says that Socrates is a non-trireme, that must also hold, since he has already agreed, absurdly, that Socrates is not a man. I thus take the idea that nontrireme is more predicable of Socrates than non-man to imply that non-trireme is in fact predicable of him. After all, given that the Protagorean admitted that even non-man is predicable of this obvious instance of man, surely he cannot balk at the idea that non-trireme is predicable of him as well. Finally, we can generalize the conclusion: 
In general, if for some object, $\mathrm{F}$ is predicable of it, not-F is also predicable Here Aristotle is saddling the Protagoreans with a further, logical principle. What this argument shows is the following. If something is generally agreed to be a man, and if it is true to say of this man that he is also not a man, then a fortiori it will be true to say absolutely anything about the man, every predication will be true. If, for instance, the Protagorean agrees that Socrates, an obvious man, is also not a man, he will have no reason to deny that Socrates is both a trireme and also not a trireme. I presented the conclusion as: if a thing's "own negation" is predicable of it, all negations (and indeed all properties) must be predicable of it. But Aristotle clearly intends more than the conditional conclusion. He intends to show that the Protagoreans are committed to the view that all properties are predicated of all things.

But here again, why should the Protagorean be willing to claim that, for instance, Socrates is not a man? Let me put the point another way. It's true for the Protagorean that everything is predicable of everything. Anytime someone makes a predication (assuming it reflects her belief), she makes a true predication. Protagoras cannot offer any rules on what one should believe or what one should predicate about a subject-at least no rules that are truth preserving. Belief alone is sufficient to guarantee truth. So there should be no reason for Protagoras to deny that anything is predicable of anything else. But it doesn't follow from what is predicable to any conclusion about what is or must be predicated. Unless we are meant to think that (a) mere predictability or believability is enough for truth, rather than actual predication and actual belief, or (b) we can somehow move from what is predicable to what must be predicated, Aristotle's attempt to link Protagoras with extreme claims like (C) or that everything is one will fall flat.

\section{Other Readings and an Attempted Solution}

It still seems that something is missing from Aristotle's argument. He requires a stronger principle than anything he has so far successfully foisted upon Protagoras. As I said, two possibilities for a stronger principle spring to mind: (a) mere predictability or believability is sufficient for truth, rather than actual predication and actual belief, or (b) we can somehow move from what is predicable to what must be predicated (or from what can be believed to what is believed). (a) seems to be ruled out by 1011b4-7; and (b), while possible, requires an argument 
which I am unable to provide. But Aristotle doesn't seem to be aware of the feebleness of his arguments, again suggesting the possibility that we have misunderstood his arguments in some important way.

\subsection{Wedin's Reading}

Michael Wedin (2003) makes a suggestion along these lines. He thinks that Aristotle's real target is not $(\mathrm{C})$, nor the claim that everything is both $\mathrm{F}$ and not-F, but a weaker, modal claim: "It is possible that every proposition and the negation of every proposition hold" (128, emphasis added). On this reading, all Aristotle would need for the argument to succeed is the possibility of belief, or predictability, not actual belief or actual predication. Wedin defends this reading by saying that PNC is "canonically formulated as a modal proposition" (p. 126), and he offers two further reasons for preferring the modalized version of the conclusion. (1) It is inherently more plausible, since it is almost surely false that there actually is universal disagreement. And (2) on the non-modal formulation, there might be a problem concerning possible objects of belief. Point (1) is of course correct: to us non-Protagoreans the weaker claim is more plausible. But (2) is problematic, as is Wedin's understanding of Aristotle's argument. In defense of (2) he writes: “...the thesis of Protagoras [i.e., (M)] is intended to hold for any proposition whatsoever, and this must mean any possible proposition. Otherwise, the thesis ceases to be a general philosophical proposal about the nature of belief. This, again, would recommend [the modal version of PNC]" (ibid.). Wedin's point here strikes me as confused. There is first the question of why he thinks (M) is a thesis about propositions, rather than only about beliefs. (I leave aside the question of anachronism in attributing to Aristotle any views at all about propositions.) Surely (M) is a thesis about beliefs or appearances, not propositions, which may or may not be believed by anybody.

Perhaps the best way to read Wedin is to reinterpret his talk of propositions in terms of beliefs, so that (M) is now understood as the thesis that possible, as opposed to actual, belief is sufficient for truth. But why should we read (M) in that way? Wedin's reading is only plausible on the assumption that $(\mathrm{M})$ is not to be understood as a biconditional. That is, he holds that (M) 
should be understood as the view that belief is sufficient but not necessary for truth. ${ }^{37}$ We have already seen some problems for this view. Here I will add only one point concerning Wedin's argument for this view, that "[o]therwise the [Protagorean] thesis ceases to be a general philosophical proposal about the nature of belief." This is wrong. The Protagorean view, as a biconditional, is just the view that belief is necessary and sufficient for truth. I can see no reason to deny that this is a "general philosophical proposal about the nature of belief." In fact, arguably Wedin's own reading should not count as one, since it concerns only potential, not actual belief.

Wedin concludes that Aristotle's real conclusion is "It is possible that every proposition and the negation of every proposition hold." This weakened conclusion, Wedin claims, "suffers no reduction in its ability to discredit [Protagoreanism]" (ibid.). Now, what counts as discrediting a thesis, particularly one so revisionary and radical as Protagoras', is difficult to assess. But Wedin's revised, modal reading of Aristotle's conclusion is too weak to discredit it in any serious way. I would say that rather than being a further claim it is a straightforward consequence of (M) requiring little argument. Aristotle's argument would be reduced to: if all beliefs are true, then whenever there is disagreement both the proposition and its negation hold. But it's not at all surprising that Protagoras is committed to the idea that it's possible that every proposition and its negation hold. This is just to say that we can disagree about anything, which follows immediately from his claim that all beliefs are true and that any proposition can be disagreed with—not a very impressive point against Protagoras.

A final problem with Wedin's suggestion is that he will have to weaken his understanding of the claim that "all things will be one." He reads the claim as everything will have all positive properties. I have shown, I think, that this sentence actually means there is exactly one object. So Wedin's reading was already weaker than it ought to have been. But even his weaker reading of the conclusion cannot be reached via his modal reading of the contrary of PNC, because all that follows from possible disagreement is possible (not actual) oneness. Wedin would have to weaken "all things have all positive properties" to it is possible for anything to have any positive property." And far from 'discrediting' the Protagorean further, this also seems to me like an obvious and straightforward consequence of the Protagorean thesis.

\footnotetext{
${ }^{37}$ In the end Wedin does endorse the idea that Protagoras "excludes matters of fact apart from believers" (p. 128). So it seems that Wedin interprets Protagoras as holding the view that all possible beliefs are true after all. This is strange, since earlier in the same paper, he argues against the biconditional reading by saying the weaker reading is "more plausible" (p. 113).
} 
Wedin's weak modal reading cannot support the conclusion that all things are one. Even if it's possible that all things have all properties and do not have them, it does not follow that everything is one.

\subsection{Other Possibilities}

My criticisms of Wedin's reading have a positive purpose. His is the rare interpretation which makes a serious attempt to salvage Aristotle's arguments, rather than simply concluding that they must be confused or weak. ${ }^{38}$ This sort of reading should, of course, be taken only as a last resort. What are we left with? The discussion so far has shown, I think, that in order to understand Aristotle's criticisms in $\Gamma 4$ and 5, we need to import something not clearly in Aristotle's text.

Speaking quite generally, Aristotle's dialectical strategy for getting his opponents to admit the PNC involves getting them to say something definite: e.g., saying that someone is a man without immediately adding that it is also not a man. Those who refuse to do this are shown to be reprobates who refuse the rules of dialectic. Such people end up saying nothing, and thereby make themselves into plants. This seems to be just where the Protagorean targets of $\Gamma 4$ end up: they end up saying both 'yes' and 'no' and also deny both of these. Aristotle responds by pointing out that affirmation and denial are opposites and when one is true, the other, necessarily, is false, but recognizes that "perhaps they might say we had assumed the very thing at issue" (passage (4), quoted above). Since PNC cannot be demonstrated and since this group of Protagoreans refused to engage in a genuine dialectic, Aristotle's remaining options are few. His main response is no one can take this sort of indifference seriously; for otherwise, like plants, they would be unable to act (1008b12-27). ${ }^{39}$

Returning to our question of how Aristotle links this group of Protagoreans with these very general claims, we can find hints that Aristotle attributes another view to Protagoras in at

\footnotetext{
${ }^{38}$ Cf. Burnyeat (1976a), who mentions Aristotle's reading and then moves quickly to Sextus Empiricus, and (1976b) where he claims the 'real Protagoras' is the one portrayed in the Theaetetus, not in Aristotle or Sextus.

${ }^{39}$ Aristotle's argument here has interesting connections to a famous anti-skeptical argument known as a Gorgon argument: skeptics, making no definite judgements would be as if turned to stone. As A.A. Long (1981: 91-2) has noted, Aristotle's description of his opponents' position at 1008a29-35 is very similar to the self-description of early Pyrrhonists.
} 
least two places. Passage (1) from chapter 4 above ends the argument with the remark, 'if the contradiction is true.' Notice also that the Protagorean in passage (4), quoted above, the Protagorean says "both 'yes' and 'no"”. Why should Aristotle think this? I submit that the best answer is that he is importing another view which helps implicate the Protagoreans in the objectionable consequences he finds. Protagoras' logos-his principal view-is (M), the claim that all beliefs and appearances are true (for those who hold them). But this needn't imply that he and his followers had no other views. In his discussion of Protagoras, the very first view Diogenes connects to Protagoras is this: "He was the first to say that there are two logoi concerning everything, these being opposed to each other" (Diogenes Laertius, Lives, IX $51=$ DK 80A1). ${ }^{40}$ The same view is confirmed in other sources (DK 80A20). If we suppose that Aristotle is making use of this view as well as (M), things become clearer. He need not assume universal disagreement. He can instead make use of the two-logoi claim, if interpreted in a certain way. It is always dangerous to try to pin down a single meaning for 'logos', but it must be attempted. The traditional interpretation of the view seems to be that there are two arguments of equal weight on whatever question. ${ }^{41}$ And we know from summaries of Protagoras' writings that he propounded arguments for and against theses, thereby setting out opposing logoi. But lacking the context in which this remark was originally found, it is not incumbent on us to interpret it that way. In fact, the context in which Diogenes places it suggests that he understood logoi here as something like 'account', as he goes on to say that from the two logoi ('hois') Protagoras propounded arguments in stages ('sunērōta'). So it could very well be that Aristotle read 'logos' here as 'account' or 'statement'. 42

\footnotetext{
40 "kai prōtos ephē duo logous einai peri pantos pragmatos antikeimenous allēlois."

${ }^{41}$ This is how Seneca (Epistles, 89.43) reads it and how most translators of Diogenes render the saying.

${ }^{42}$ Another possibility, for which I thank Jean-Louis Hudry is that the apparent lacuna in Aristotle's argument can be filled with Aristotelian premises. One assumption I have been making is that in order to count as a belief-a doxa-there must be someone who believes that. But this is arguably a misunderstanding of what a doxa is for Aristotle. On Aristotle's view, a doxa is simply a thought, an idea, which needn't be even entertained as true to count as a doxa. If we add this to the Aristotelian claim that it is statements which have truth-value, we can summarize Protagoras' view as follows: any statement, whether actually believed or not, is true. The idea that there are unbelieved truths is thus reduced to the idea that there are truths beyond statements, which for Aristotle is absurd. While this is a helpful suggestion, it would require at the very least a long foray into Aristotle's logical views, which I cannot attempt here. I would also question whether Aristotle's own views ought to be imported in this context. Aristotle is of course appropriating Protagoras' views for his own purposes, but I prefer to find a way his portrayal of Protagoras in a way Protagoras would have recognized.
} 
I have argued that length that nothing can explain why Aristotle would have thought (M) alone should lead to the conclusions he connects the Protagoreans with. But if Protagoras also holds that there are two accounts for everything, things become clearer. We can now see why Aristotle might have thought Protagoras is committed to the view that the contradiction is true, viz. because he holds there are two logoi concerning everything. So if Socrates is a trireme, according to Protagoras he is also not a trireme, since the one logos must be coupled with its contrary. And given that there are two accounts for everything, the Protogrean must admit both that Socrates is and is not a trireme. This also helps explain why Aristotle repeats his conclusion in terms of the same thing rather than everything: the two-logoi view presupposes that they both concern the same thing, thus connecting this point with some remarks I made in $\$ 3$ concerning different ways the Protagoreans might have dealt with apparent conflict.

What I have offered here is at best a sketch of a possible solution. Further work is needed to connect these arguments to Aristotle's proof of PNC and explain how he connects Protagoras' views to those of others-to say nothing of Protagoras' portrayal in Plato. A fuller account would also need to discuss the logical connections between the two-logoi view and (M). Is it incumbent upon a Protagorean to accept the two-logoi view merely in virtue of accepting (M)? Or are they logically separable? If so, why should a Protagorean adopt the two-logoi view? Is the view dependent on (M), in that it is true if and only if it is believed? And why are there exactly two logoi? Is it that every disagreement is reducible to an affirmation and denial? All these questions are still in the air. But for now, I hope to have made some little progress on these puzzling passages. ${ }^{43}$

Evan Keeling

Universidade de São Paulo

\footnotetext{
${ }^{43}$ I am grateful to Dan Devereux, Paula Gottlieb, Jean-Louis Hudry, and Marco Zingano for discussion and comments on earlier versions of this paper. I am also grateful to an audience at the University of São Paulo.
} 


\section{Bibliography}

Burnyeat, M.F. 1976a. "Protagoras and Self-Refutation in Later Greek Philosophy", Philosophical Review 84: 44-69.

Burnyeat, M.F. 1976b. "Protagoras and Self-Refutation in Plato's Theaetetus", Philosophical Review 85: 172-95.

Code, A. 2010. "Aristotle and the History of Skepticism" in Ancient Models of Mind: Studies in Human and Divine Rationality, eds. Nightingale and Sedley. Cambridge: Cambridge University Press.

Erginel, M. 2009. "Relativism and Self-Refutation in the Theaetetus", Oxford Studies in Ancient Philosophy 36: 1-45.

Gottlieb, P. 1994. "The Principle of Non-Contradiction and Protagoras: The Strategy of Aristotle's Metaphysics IV 4." Proceedings of the Boston Area Colloquium in Ancient Philosophy. Vol. VIII: 183-209.

Keeling, E. unpublished. "Aristotle and Protagoras on the Infallibility of Proper-Object Perception: Metaphysics Г 5, 1010b1-1011a2".

Kirwan, C. 1993. Translation with notes. Aristotle's Metaphysics Books Gamma, Delta and Epsilon. 2nd edition. Oxford: Clarendon Press.

Lee, M.K. 2005. Epistemology after Protagoras: Responses to Relativism in Plato, Aristotle and Democritus. Oxford: Oxford University Press.

Long, A.A. 1981. "Aristotle and the History of Greek Scepticism” in Studies in Aristotle, ed. D.J. O'Meara. Washington: Catholic University of America Press, 79-106.

Ross, W.D. 1924. Aristotle: Metaphysics. Text with translation and notes, 2 volumes.

Tredennick, H. 1933. Aristotle: Metaphysics Books I-IX, Loeb Classical Library. Cambridge: Harvard University Press.

Wedin, M.V. 2003. "A Curious Turn in Metaphysics Gamma: Protagoras and Strong Denial of the Principle of Non-Contradiction." Archiv für Geschichte der Philosophie 85 (2): 107-130.

Wedin, M.V. 2004a. "Aristotle on the Firmness of the Principle of Non-Contradiction," Phronesis 49 (3): 225-265.

Wedin, M.V. 2004b. "On the Use and Abuse of Non-Contradiction: Aristotle's Critique of Protagoras and Heraclitus in Metaphysics Gamma 5." Oxford Studies in Ancient Philosophy 26: 213-239. 